This article was downloaded by: [New York University]

On: 19 May 2015, At: 01:46

Publisher: Routledge

Informa Ltd Registered in England and Wales Registered Number: 1072954

Registered office: Mortimer House, 37-41 Mortimer Street, London W1T

3J H, UK

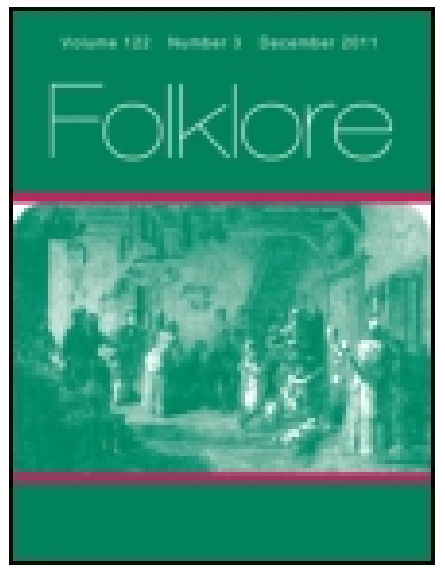

\title{
Folklore
}

Publication details, including instructions for authors and subscription information:

http:// www. tandfonline.com/loi/ rfol20

\section{The Sociological Significance of Myth.}

W. H. R. Rivers

Published online: 06 Feb 2012.

To cite this article: W. H. R. Rivers (1912) The Sociological Significance of Myth., Folklore, 23:3, 307-331, DOI: 10.1080/ 0015587X.1912.9719532

To link to this article: http:// dx. doi. org/ 10.1080/0015587X.1912.9719532

\section{PLEASE SCROLL DOWN FOR ARTICLE}

Taylor \& Francis makes every effort to ensure the accuracy of all the information (the "Content") contained in the publications on our platform. However, Taylor \& Francis, our agents, and our licensors make no representations or warranties whatsoever as to the accuracy, completeness, or suitability for any purpose of the Content. Any opinions and views expressed in this publication are the opinions and views of the authors, and are not the views of or endorsed by Taylor \& Francis. The accuracy of the Content should not be relied upon and should be independently verified with primary sources of information. Taylor and Francis shall not be liable for any losses, actions, claims, proceedings, demands, costs, expenses, damages, and other liabilities whatsoever or howsoever caused arising directly or indirectly in connection with, in relation to or arising out of the use of the Content.

This article may be used for research, teaching, and private study purposes. Any substantial or systematic reproduction, redistribution, reselling, loan, sub-licensing, systematic supply, or distribution in any form to anyone is 
expressly forbidden. Terms $\&$ Conditions of access and use can be found at http://www.tandfonline.com/page/terms-and-conditions 


\section{THE SOCIOLOGICAL SIGNIFICANCE OF MYTH. ${ }^{1}$}

BY IV. H. R. RIVERS.

\section{(Read at Meeting, June 19th, 1912.)}

To those engaged in the attempt to trace out the history of social institutions among people of rude culture, the myths and traditions of the people themselves form a natural and attractive field of inquiry. At the present time, however, there is the widest divergence of opinion as to the value of this kind of knowledge. By some workers such narratives are used as evidence without hesitation, while by others. they are put wholly on one side as the pure fruit of imagination, having no relevance where facts are concerned.

A striking example of this divergence of treatment is to be found in the utilisation of Arunta narratives by Messrs. Spencer and Gillen ${ }^{2}$ and Dr. Frazer, ${ }^{3}$ and their scant rejection by Mr. Andrew Lang " as traditions "dictated by the logic of fancy," and therefore, it is assumed, of no value as evidence. It does not seem to have occurred to these workers, ${ }^{6}$ nor, so far as I am aware, has it occurred to others,

1 I am indebted to Miss C. S. Burne, Miss Jane IIarrison, and Mr. H. M. Chadwick for suggestions which have led me to add to, or modify, this paper since it was read before the Folk-Lore Society.

-The Native Tribes of Central Australia, pp. 207, 209, and The Northern Tribes of Central Australia, p. 320.

- Totemism and Exogamy, vol, i., p. 238. Man, vol. x. (1910), p. 119.

- Except in so far as Messrs. Spencer and Gillen lay stress on the divergence of tradition from present customs. 


\section{The Sociological Significance of Myth.}

to inquire whether it is possible to lay down any general principles which may enable us to assign its proper value to such evidence. It is the purpose of this paper to formulate one such principle and inquire to what conclusions it may lead us.

I must first say something about the sense in which I propose to use the term 'myth.' At the present time this word is used with many different meanings. By some it is limited to narratives which give an account of the doings of gods or of those who possess in some measure divine characters; to others a narrative is only a myth if it stands in a definite relation to ritual and serves to explain and justify this ritual; by others the term is used more widely, but is limited to narratives which give an account of or explain natural as opposed to social phenomena.

In the present state of our knowledge the chief justification of classifications and definitions lies in their usefulness, and a classification which may be useful from one point of view may not necessarily be so from another. I approach the subject of myth in this paper in its relation to the history of culture, and from this point of view, if from no other, the limitations implied by the usages I have mentioned are neither helpful nor necessary.

The general class of which myths form one group are narratives which give a concrete account of events. By thus laying stress on the concrete nature of "narratives" I intend to exclude the abstract accounts of events given by science.

From the point of view of the history of culture the first grouping of narratives depends on whether they are or are not historical, whether they are records of events which have actually happened or the work of the human imagination. We can be confident that even those narratives of peoples of rude culture which come nearest to history contain imaginative elements, but this only makes it the task of the student to distinguish the two elements from one another. 
The first line of cleavage of narratives and of their elements, then, is into the historical and the imaginative. The latter class may be further broken up into two main sections, viz. those which purport to give an account of or explain any portion of the universe, and those which have no such purpose but are purely fictive, and I propose to distinguish these two sections as myth and fiction respectively. According to this mode of classification a myth is a narrative which gives an account of the coming into being of man himself or of any feature of his environment, natural or social. ${ }^{8}$ Not only will it include narratives which account for and justify man's religious practices, and thus extend to all which describe the doings of gods and serve to explain the general character as well as the details of ritual, but it will also include narratives which tell how there arose features and motions of any objects in sky, sea, or land. It will range in its connotation from the most elaborate doings of a god, in so far as these are not historical, to the origin of the elephant's trunk or the cause of a cleft in a rock.

I am not concerned in this paper with the group of narratives I include under fiction, and need only say that, though they often take the form of tales which give an account of events supposed to have happened, they differ from myths in having no explanatory motive. Their purpose is purely æsthetic, and, though such fictive tales undoubtedly exist among people of rude culture, they are probably less frequent and less important than among the civilised. Only one point need be noted here, viz. that a large proportion of the narratives of lowly culture are probably myths which have been transmitted from people

- This definition limits the term "myth" to narratives which have an ætio. logical or explanatory motive. I have, however, expressly avoided the use of the word "explain" in the definition, because this term bears a rationalistic connotation which makes it a very inexact means of expressing the mental attitude of those among whom myths arise. For want of a fully appropriate word, however, I shall speak of myths as explanatory in the general body of the paper. 
to people, in which process their ætiological character has been lost or obscured.

The classification of narratives, then, which I propose is into historical traditions, myths, and tales. According to my use of the word, a myth is the pure product of the human imagination, an attempt to express the wonderful and the mysterious.

My definition of myth does not include a frequent feature of narratives in which actions or sayings are assigned to persons other than the real agent. Wonderful stories tend to cluster round the lives of exceptional men and round superhuman beings, and such stories are often called myths, but, except in so far as they help to show the divine or superhuman character of the being to whom they are attributed and thus assist in accounting for the mysteries of the universe, they would not come under my definition.

I may point out that my mode of defining myth corresponds closely with that of current English usage as indicated by the definition of Murray's dictionary, viz. "a purely fictitious narrative usually involving supernatural persons, actions, or events, and embodying some popular idea concerning natural or historical phenomena." My usage is more definite in its omission of the qualification beginning with the word "usually," and it has the advantage of avoiding the ambiguous word "supernatural," but the two agree in the important point that the term applies to all natural or historical, i.e. social, phenomena.

My definition also agrees in essence with current German usage as indicated by Bockh's Encyclopaedie, which is accepted by Ehrenreich," viz, "der sinnliche in Personifikationen gegebene Ausdruck der gesammten ethischen und physischen Erkenntnis." Here again the word is made to cover the whole of human experience, and it also clearly implies the explanatory purpose of myth. The definition might be freely translated "the concrete expression of - Die allgemeine Mythologie, Leipzig, 1910, p. 6. 
human knowledge, social and natural, by means of personification." A doubtful point is how far the term Personifikation necessarily implies anthropomorphic expression. If this term can be stretched to include the representation of ideas in animal or other non-human concrete forms, there would be little if any difference between the two definitions. R. M. Meyer ${ }^{8}$ has expressed in brief but pregnant form the main idea of my definition. According to him a myth is any part of the universe seen from the point of view of primitive man, "ein Eckchen Welt, angeschaut durch das Temperament eines primitiven Menschen."

Myths may deal with social topics in three distinct ways. First, it may be the primary motive of a myth, or of some part of a myth, to give an account of the coming into being of a social institution. Next, a myth may have a social setting. The whole myth may be coloured by some social atmosphere; thus, in the myths of a totemic people there will be a totemic colouring, shown by reference to persons in such a way as to leave it doubtful whether they are human beings or animals. Thirdly, a myth may include incidental references to specific social events, such as a special form of marriage. ${ }^{9}$

The significance of the social setting and of incidental references to social events is very great, but it is so obvious and, I think, so generally admitted, that I do not propose to deal with these aspects of myth in this paper. When a social condition is mentioned incidentally or is revealed by the general colouring of a myth, we can be confident that it is not the pure product of imagination, but has a definite historical value. Social incidents, still less the general colouring of a myth, could never appear unless they had

- Altgermanische Religionsgeschichle, 1910, p. 9.

- A good example of such an incident is to be found in a narrative recorded by Dr. Codrington (The Melanesians, p. 384), in which a man marries one of the wives of his maternal uncle. 
their roots in the social constitution either of the people who narrate the myth or of those from whom the myth has been derived.

I propose, then, to accept without question the value, as historical evidence, of incidental references to social conditions and of the social setting of mythical narratives. It is not with these aspects of myth that it is the special purpose of this paper to deal, but with that kind of myth the primary motive of which is to account for social phenomena. I may point out at once a feature of such myths which differentiates them from myths having natural phenomena as their subject. When people relate a story which provides an anthropomorphic or theriomorphic interpretation of the moon's periodical changes, or narrate the events which produced the features characteristic of some animal, it is clear that we have to do with myth. When, on the other hand, they give an account of events which led to the appearance of a form of social structure or of the mode of performing a rite, we have no such immediate certainty that we have to do with myth. It is possible that the people may be preserving the memory of an actual occurrence; that we may have to do, not with myth, but with historical tradition. A possibility, then, which must always be kept in mind in dealing with narratives which appear to be social myths is that they may not be myths at all but historical traditions, or combinations of both history and myth.

The first fact which meets us in our inquiry is that narratives of a mythical kind which serve to account for social conditions occur but seldom among the records of savage or barbarous peoples. Accounts dealing with features of the sun, moon, and stars, of land and sea, of winds and weather, of animals and plants, are abundant, but it is only exceptionally that we meet with narratives which serve primarily and especially to account for social conditions. This predominance of natural phenomena as 
the object of myth is so great that in many works on mythology the social myth is not mentioned. Thus, no reference is made to it in the three chapters devoted to Mythology in Tylor's Primitive Culture, nor does van Gennep refer to it in his recent work La Formation des Légendes. ${ }^{10}$ Its existence is definitely recognised by Ehrenreich, ${ }_{11}^{11}$ but, in so far as Wundt ${ }^{12}$ deals with it at all, he includes it under the general heading of "Natur-Mythus."

By some of these writers, as by van Gennep, the kind of narrative with which I propose to deal this evening is explicitly excluded by definition from the class "myth," 13 and in view of its exclusion by some, and its neglect by other mythologists, it may be well to give an instance of a narrative, undoubtedly mythical, which has a definitely social subject. In one district of the Melanesian island of Santa Cruz, there are clans, one of which has as totem a bird called taklai, while most of the others take their names from fishes. It is narrated that once the taklai bird hatched out a brood of young by the side of a stream. The nestlings were carried out to sea by the stream and were taken in charge by various fishes, and it was the birds thus taken in charge who were the founders of the different clans. It is clear that we have here a narrative which gives an account of the origin of the totemic organisation, and explains why the taklai bird is the totem of one clan and fishes the totems of others. Taken apart from its social context this might be regarded as a purely fictive tale having the doings of animals as its subject, but the social setting in which it is found shows that it has an atiological character. It is either a pure product of the constructive imagination seeking for an explanation of social conditions, or an instance of reversal of the more common anthropomorphic tendency of mankind

\footnotetext{
10 Paris, 19 to.

11 Die allgemeine Mythologic, Leipzig, 19 ro.

1 Völkerpsychologie, Mythus u. Religion, vol. ii., pp. 294, 341.

1s See Internat. Wochensch. f. Wissenschaft, Kunst u. Technik, 1910, vol. iv., p. 1167.
} 
in which the doings of men have, as befits a totemic people, been transmuted by the mythic fancy into the doings of birds and fishes.

It is rarely that one meets with a narrative concerning social origins of which the mythical character is so obvious. More generally the narratives of rude peoples which deal with social topics are of the kind often known as culturemyths or sagas. ${ }^{14}$ Such myths or sagas give an account of the introduction of various elements of the culture of the people who narrate them, but, in general, it is the introduction of material objects and of magical or religious rites which are especially recorded in these narratives. It is only exceptionally that there is any explicit reference to the introduction of social institutions.

Having now defined my terms and the scope of the subject with which I propose to deal, I can turn to the special business of this paper, the attempt to discover a general principle which may guide us in the attempt to assign their proper value to myths as evidence of the history of social institutions. For this purpose it is necessary briefly to survey the whole field of mythology to see whether any definite proposition can be laid down concerning the objects which are especially prone to become the subject of the mythopoeic tendency.

The principle I venture to suggest is that it is not the especially familiar and uniform which becomes the subject of myth ; that which is ever with us in the same form does not excite the mythic fancy, but for this purpose there is necessary such an element of variety and of apparent, if not real, inconstancy as will attract attention and arouse curiosity.

Let us now survey different fields of nature admittedly the subject of myth, and see how far this proposition can be justified. I will begin with myths having animals as

\footnotetext{
1 Sagas form a class of narrative dealing with heroes in which historical and mythical or fictive elements are blended.
} 
their subject. Here, I think, there is definite evidence that it is not the especially familiar which becomes the subject of myth. Thus, in Melanesia, the animal which is ever present in the minds of the people, the subject of their daily, almost hourly, thought, is the pig, and yet I know of hardly a myth dealing either exclusively or mainly with this animal. It is about such features as the long tail of the rat, the red head of the rail, the thinness of one fish, and the grinning appearance of another, that myths have arisen and are still told by the people. Familiar animals may become the subject of myth when they are the object of religious ritual, as among the Todas, and myths may arise to explain exceptional features of a familiar animal, especially those which distinguish him from man, such as a wide mouth and the lack of speech, but with these exceptions I believe it to be a general rule that man has not mythologised about the domestic animals with which he is in daily contact, but rather about those he sees only occasionally, so that special features of their structure or behaviour have not a familiarity which has bred contempt and made them unfit subjects for the play of imagination.

Again, of features of land and sea, it is not the land which he clears and tills, ${ }^{15}$ or the haunts he visits habitually to hunt or fish, which are the subject of myth, but rather strangely shaped rocks or dangerous reefs which he sees only occasionally, and then in such a way as especially to impress the imagination, and thus become the subject of the mythic fancy.

The same principle is even more striking in the case of meteorological conditions. Myths concerning the winds are well developed in parts of the world where their direction and strength are variable and uncertain, but in such a

\footnotetext{
15 It is only when there is anything exceptional in the nature of this land that it will become the subject of myth. Thus, if an island has red earth only in one locality, it will naturally attract attention and be likely to form a subject for the play of imagination.
} 
region as Melanesia, where the seasons are remarkably constant and regular, myths about the winds scarcely occur. The importance of these winds and their accompanying seasons in the life of the people is enormous; in one form or another ideas connected with them permeate the whole lives of the people, and yet it is not about them that one finds myths, but rather about the inconstant appearance of the rainbow or the meteor.

I turn now to the heavenly bodies, which probably at all times and in all places have been the most frequent subject of myth. In recent works on mythology, especially in Germany, the prominent place formerly occupied by the sun has been largely taken by the moon. It is in the moon that many modern mythologists see the subject of the early speculations they believe to underlie so many of the myths of the world, both civilised and uncivilised. Without in any way committing myself to accept the general views of the modern German school, I believe that it is right in the importance it attaches to the moon rather than to the sun, at any rate in tropical countries, and in the ruder stages of culture. If this be so, it is exactly what is to be expected on the principle I am now trying to establish. In tropical countries the daily course of the sun is almost exactly the same from day to day, year in, year out, while the variations of the moon are such as can hardly fail to arouse attention and wonder. Not only are there the changes of its times of appearance in relation to the distribution of night and day, not only is there its total disappearance for a time in every month, but there are such changes of form as cannot but arouse the speculative tendency, if it is to be aroused by anything. While the constancy of the sun's movements make it the daily means of orientation in time, its uniformity and familiarity is such as to make it a far less appropriate subject for the mythic fancy than the changeable and inconstant moon. ${ }^{16}$

10 The greater apparent inconstancy of the moon's course has not been the 
You will have noticed that I have qualified this opinion by limiting its application especially to the tropics. In more temperate latitudes, where there are great variations in its yearly course, the sun may on my principle be expected to bulk more largely in mythology, and, though it is taking me from my proper subject, I cannot refrain from a passing suggestion that the principle I am trying to establish may serve as a guide to the home of myths, highly developed myths having the sun as their subject-matter being more likely to have arisen in high latitudes. ${ }^{17}$

There are certain frequent subjects of myth which are so constantly present and so familiar as to awaken doubts concerning the sufficiency of the generalisation I am trying to establish. Thus, fire is so familiar a feature of the surroundings of people at all known stages of culture that one would hardly expect it to be a frequent subject for the play of imagination. There are, however, certain features of fire and fire-making which serve to account for this apparent exception to our rule. Probably nowhere among people of low culture is the making of fire a frequent and familiar occurrence. Every one who has lived among rude people must be struck by the care taken to keep the fire alive on the hearth. Though fire is familiar, the act of making fire has just that occasional and recurrent character which affords the most suitable soil for the growth of myth. Further, fire is made by different methods, and it may well be that many of the myths dealing with fire have their basis, not in the origin of fire itself, but in the introduction of some new mode of making it.

only motive for its prominence in myth. The supposed connection of the moon with ideas of fertility (cf. E. J. Payne, History of the New World called A merica, 1892, vol. i., p. 493), and with physiological conditions has certainly been an important motive working in the same direction. Further, it is probable that the visibility of the moon at night, when the emotions underlying the mythopoeic state are especially prone to arise, has been another very important factor.

11 The bearing of this point on the problem of the original home of the Aryans is obvious. 


\section{$3^{18}$ The Sociological Significance of Myth.}

Another frequent subject of myth is even more familiar than fire. If myths do not arise about the familiar, we should not expect to find the narratives of rude culture dealing with the origin of man himself or of the part of the earth on which he lives. The wide prevalence of creationmyths seems at first siglit to form such an exception to my generalisation as to put it wholly out of court. At the present moment I am content thus to mention the problem raised by this exception, and shall return to it later when the general argument of my paper will have given us the clue to its solution.

The examination of nature-myths has now led us to the principle that people do not mythologise about the uniform and the familiar, and I proceed to inquire what aspects of social life we should expect to find the subject of myth if this principle also holds good of myths having social conditions as their topic. The point on which I wish especially to lay stress as the foundation of my argument is that, if people do not make myths about the very familiar, social organisation is the very last aspect of social life which one would expect to be their subject. By social organisation I mean the fundamental setting in and around which social events take place,- - such institutions as the family and clan and the relationships set up by membership of these social groupings. Of all aspects of social life this is the most constant and all-pervading. We often speak of it in general as social structure, because it forms the foundation and framework of the whole social life, and, if there is anything in the principle I have stated, I should no more expect to find its origin the subject of myth than I should expect to find myths about the origin of the floors and walls of our houses.

There is a very striking difference between phenomena belonging to the fundamental institutions of social organisation and those connected with other aspects of human life. A man who is carrying out a religious rite is doing some- 
thing special, and, though religious practices pervade the lives of those of ruder culture far more thoroughly than among ourselves, there is, in every practice which can be called religious, an element of separateness from the ordinary life which excites the attention and makes the action one likely to excite curiosity and wonder. Indeed, the element of separateness from ordinary life is one of the essential features of religion. Similarly, one who goes out hunting, even though he does so every day, is doing something which he is not always doing. He is entering upon a mode of activity which brings into being a special set of ideas and emotions. The fundamental social relations, on the other hand, those of the family or clan, for instance, are in far more constant action, and are at the same time less obtrusive. They are present as an integral part of every activity upon which a man enters, and there is no intermission in their action. Not even during the partial unconsciousness of sieep do they cease to play a part, but here, as in the waking state, they form only the setting for other appearances far more calculated to excite the speculative tendency.

It may be urged that there are events such as marriage, in which the social interest is dominant, which might be expected to awaken curiosity, and thus excite speculation concerning origin in a pre-eminent degree. Here again, however, it is not the purely social elements which are the most obtrusive. In marriage, for instance, the features of the occasion which are of the most fundamental social significance pass almost without notice. The relationship of bride and bridegroom and other purely social factors which serve to regulate the marriage as a social institution are so obvious that, though they must have attracted attention during the arrangement of the marriage, they will have become part of the established order by the time the marriage ceremonies are performed, and will sink into insignificance beside the more purely ritual features of the occasion. 
Further, in a rude state of culture, the fundamental social relations are even less obtrusive than in civilised communities. Among ourselves there has come to be a more or less sharp line of distinction between relatives and friends, and it is at important moments of life, such as birth, marriage, and death, that such distinctions are brought more obtrusively than usual to our notice. Even then, however, our imaginations are not excited by the fact, and, if we are led to indulge in speculation at all, these social relations are not their most probable subject. Still less are they likely to become the subject of speculation at ruder levels of culture, where the distinction between relative and friend can hardly be said to exist.

I shall have later to consider an important exception to the rule I am now formulating, but for the present I conclude that of all aspects of human life those of purely social character are the least likely to awaken speculative interest and become the subject of myth.

We should thus expect that myths having social organisation as their subject should be absent or very rare. It is only among people of advanced culture that we should expect to find a speculative interest in the origin and development of social institutions, and then we might expect that the speculations would be clothed, not in the form we know as myth, but in that different though allied form of expression we call science. It is therefore a remarkable and startling fact that there are few peoples of the earth whose myths deal more definitely and explicitly with social conditions than the Australians, who, while far more advanced than was once supposed, yet undoubtedly occupy a very lowly place in the scale of human culture. It is this paradox which will occupy our attention for the remainder of this paper.

The narratives with which I propose especially to deal are those of the Arunta, Dieri, and other tribes of central Australia. These people narrate long and complex 
accounts, full of circumstantial detail, concerning beings who introduced various rites, such as circumcision and subincision, and certain implements of material culture, such as the stone knife and the bull-roarer. In general, these narratives are good examples of the kind known as culturemyth, but the point in which they are exceptional is in the prominence they give to social institutions. Not only do they give an account of the introduction of totems, but they even account for the institution of so purely social an institution as exogamy. From two widely separated parts of the continent Howitt 18 records myths dealing with the formation of moieties or clans, while accounts of the institution of marriage regulations occur also in the narratives of the Arunta recorded by Spencer and Gillen and by Strehlow. These are elements of the social order so fundamental and so familiar to those who practise them that they seem the most unlikely subjects for myth. Widespread as is the institution of exogamy among those of rude culture, I know of few other examples ${ }^{19}$ of native narratives, mythical or otherwise, dealing with its origin, and it is therefore most necessary to inquire why they should occur among the aburigines of Australia.

In the search for motives which will explain the prominence of social forms in the narratives of the Australians, a fact which will probably occur to every one is the great complexity of their social organisation. The social arrangements of these people are so complex that it is only by prolonged and severe effort that even the trained sociologist succeeds in understanding them fully, and probably there could be counted on the fingers of one hand the sociologists

18 The Native Tribes of South-East Australia, pp. 480, $49 \mathrm{r}$.

10 As examples from Melanesia, Jos. Meier, (Mythen und Erä̈hlungen der Kiistenbewohner der Gazelle-Halbinsal (Neu-Pommern), 1909, p. 23), gives a myth of the origin of the dual organisation in New Britain, and Suas, (Anthropos, I912, vol. vii., p. 47), records a similar account from Lepers' Island in the New Hebrides. 


\section{The Sociological Significance of Myth.}

who possess even an approximate mastery of their complexities. One is therefore tempted to suggest that it is this complexity which makes the social organisation of the Australians so obtrusive that it comes into the focus of direct and fully conscious attention. If this argument from our own incapacity stood alone, I should attach little importance to it. It would be the utilisation of a line of argument which I believe to be thoroughly vicious, being based on the idea that because an institution is strange and unintelligible to us, it must therefore be so to those of whose life it forms an integral part. But this argument does not stand alone. The accounts of various writers make it probable that the social regulations of the Australians do not work smoothly; that doubtful cases frequently arise which have to be settled by the elders; and there seems also to be little doubt that these knotty points arise, not merely in personal and concrete matters, but may involve the interpretation and even in some cases the modification of customary social regulations. So far as I am aware, the Australians are again exceptional in this respect. In places with which I have myself had to deal, the chiefs or elders or other governing element of the community often have to decide matters of fact, such as the exact relationship of persons to one another, the paternity of a child, the right of persons to land, etc., but it is most exceptional that they have to interpret or modify social regulations. The only example of which I can think is when there arises the necessity for the interpretation of the extent of the classificatory principle of relationship, and I do not know of a single instance in which there has been such deliberate modification of social regulations as seems to occur in Australia.

There is reason to believe, then, that the complexities of Australian social structure are such as to bring it frequently into focal attention, and make it a matter with an obvious and vivid interest. It is at least remarkable that a people 
whose customary narratives deal so largely with social matters should at the same time be one whose social structure so frequently becomes the object of definite attention and interest.

My first suggestion, then, is that social relations are prominent in the myths of Australia because these relations are so complex that they are forced more frequently and obtrusively than elsewhere into the focus of social attention, and thus acquire such interest as to arouse wonder and speculation. I have now to point out certain facts which lead me to look elsewhere for the chief motive we are seeking, though it is not improbable that the element of complexity may be one factor tending to give persistence to the narratives, even if it played no part in their formation.

Before I proceed to point out the difficulties which lead me to look further afield in my search for an explanation of the exceptional character of Australian myth, I must consider one prominent feature of Australian social mechanism. I have elsewhere ${ }^{20}$ briefly drawn attention to the fact that throughout Australia there are found in combination two forms of social structure which elsewhere, as in Melanesia, are wholly distinct and apparently belong to two quite different cultures. These forms of structure are the dual organisation and the organisation in totemic clans. The dual mechanism of Australia is much more complicated than any of which we know elsewhere, having added to it the system of matrimonial classes, but, whether there be four or eight of these matrimonial classes, they remain in essence modifications of the dual system, while the totemic system seems, in many cases at any rate, to be an additional mode of social grouping.

The fact to which I wish now to call attention is that it is the totemic aspect of social life which is especially pro-

${ }^{20}$ Address, Section II, British Association, 1911. See Report for I9I1, p. 490 , or Nature, 1911, No. 1xxxvii., p. 356. 


\section{The Sociological Significance of Myth.}

minent in the mythical narratives of the Australians. The names of matrimonial classes occur continually as part of the general setting of the myths, but the matter with which these narratives primarily deal is the appearance and conduct of beings who had the half human, half animal features which are so characteristic of the mythical personages of totemic peoples.

I know of only one definite case in which an Australian myth gives an account of the origin of the dual system, viz. the account given to Siebert by the Wurunjerri people which has been recorded by Howitt. ${ }^{21}$ According to this account, the Kulin, of whom the Wurunjerri form only one tribe, were told by Bunjil to divide themselves into two parts. "Bunjil on this side and Waang on that side, and Bunjil should marry Waang, and Waang marry Bunjil." In his account of this narrative Howitt compares it with the well-known myth of the Dieri, ignoring the fact that in the latter it was the totemic groups which were instituted either by the order of a superior being or by the commands of the elders. It is noteworthy that, though the Wurunjerri have only two moieties, one is definitely connected with a totem. There is little doubt that we have to do with a much modified social system, and this isolated example of a myth concerning the origin of the dual organisation suggests that it may be a survival of a totemic myth, the subject of which has been transferred to the dual system.

In another case in which the matrimonial classes are concerned, the evidence is conflicting. According to Spencer and Gillen, ${ }^{22}$ the four class names of the Arunta were first conferred by certain Ullakupera or little hawk men, these Ullakupera men already belonging to these classes. ${ }^{23}$ It is expressly stated that it was the names, 21 Op. cit., p. 49r.

${ }^{22}$ The Native Tribes of Central Australia, p. 396.

22 Op. cit., p. 394 . 
Panunga, Bulthara, Purula, and Kumara, which were conferred by the visitors, and the narrative does not say that these people instituted the classes, much less the dual organisation which underlies them.

The narratives recorded by Strehlow ${ }^{24}$ give a somewhat different account. In one place ${ }^{25}$ it is said that, when the rella manerinja or intarinja (the Inapertwa of Spencer and Gillen) were first visited by the altjirangamitjina (the Alcheringa ancestors of Spencer and Gillen), they were already divided into eight classes. Later ${ }^{26}$ it is stated that, when Mangarkunjerkunja, whose totem was a fly-catching lizard, came from the north, he instituted the rules of marriage between the classes, which, it is again stated, had been already distinguished from the beginning.

Taking the accounts of Strehlow and of Spencer and Gillen together, it seems clear that the narratives do not give an account of the formation of the dual system or of the matrimonial classes, but of some change in the functions of this social grouping in the regulation of marriage.

The position to which we have now been led is that, when Australian myth deals with the origin of social institutions, it is usually the totemic system which forms the special topic of the narrative, and not the dual system and matrimonial classes which seem to form the essential basis of the social structure. This suggests that Australian totemism has become the subject of myth, not through its social importance but for some other reason, and for this other reason we have not far to seek. I suggest that it is the magico-religious importance of totemism, and not its social functions, which have made it so exceptionally and prominently the subject of Australian myth. If so, it will follow that the preoccupation of Australian narrative with social forms is largely apparent rather than real, an appear-

"Mythen, Sagen und Märchen des Aranda-Stämmes in Zentral.Australien, Frankfurt-am-Main, 1907.

2s Op. cit., p. 3 . 20 Op. cit., p. 6. 
326 The Sociological Significance of Myth.

ance due to the exceptional development of the magicoreligious aspect of totemism in Australia.

Even, however, if it be conceded that the prominence of social forms in Australia is a secondary result of the close connection of these social forms with magico-religious functions, we are still left with the fact that Australian myth does not deal solely with the magico-religious aspect of totemism, but that its purely social aspect occurs explicitly as the direct subject of myth. We cannot get over the fact that, even though the social side of totemism may be subsidiary, it yet has a social side which is the subject of myth. Further, we have the fact that Australian myth has not altogether passed over the dual organisation and matrimonial classes which have, so far as we know, a more purely social function. Though I have lightened my task by bringing in the magico-religious importance of totemism as the main motive for its prominence in myth, $I$ have not disposed of the whole problem, but am still left with the necessity of explaining how the social aspect of totemism and the purely social dual system have come to be subjects of myth.

I have now to point out a condition which would make social forms such an object of attention, and even of mystery and wonder, that we may readily understand their becoming. a fit subject for the mythic fancy. The statement on which I have hitherto relied, that social structure is too familiar to become the subject of myth, is only true solong as a people remains homogeneous and undisturbed by outside influence. If the social system of the Australians has been the result of a process of development working itself out within a homogeneous people, I cannot believe that there would ever háve arisen myths so intimately associated with social institutions as those of the Arunta and other Central Australian tribes. If, on the other hand, the Australians are not a homogeneous people, but if their social institutions have arisen through a blend of widely different forms 
of culture belonging to different peoples, then there would be full opportunity for wonder and mystery such as are necessary to set in action the mythic fancy.

Imagine a society founded on the simple dual principle coming into contact with a people organised in totemic clans and having as a fundamental part of their psychology the belief in the identity of certain groups of men with certain kinds of beast or plant. Here we have every ground for curiosity amounting to wonder and for a sense of mystery amounting to awe. To the non-totemic people the social grouping founded on identity with animals must appear strange and wonderful; the totemic members of the united people would be plied with questions concerning the motives and causes of the strange relation, and ample scope would be allowed for the play of imagination out of which myths arise.

I have elsewhere suggested ${ }^{27}$ that the various forms of social organisation found in Australia are the outcome of such a blend of peoples as I have just asked you to imagine, and this paper only takes the suggestion a step further. If the narratives of the Australians are myths, I can only see in them evidence of the blending of peoples; it may be of peoples possessing widely different forms of totemism, or it may be of a totemic people with one to whom relations with totemic animals and plants were altogether new and strange.

At this point I must return to the creation-myths which seemed to furnish so great an obstacle to the acceptance of the generalisation that man does not make myths about the familiar. Here, again, I believe that the explanation lies in the complexity of culture. So long as mankind lives undisturbed, so long will his own existence and that of the earth on which he lives form such a part of the established and constant order of his life that his imagination will be untouched. If, however, men come from elsewhere, and 
especially if these have physical features and language different from his own, immediately will mystery and wonder be aroused. Myths will arise, or, if the strangers have a culture of which creation-myths form part, these will be transferred and transmitted and become part of the permanent heritage of the people.

It is noteworthy that creation-myths occur among the Australians, and that they are intimately blended with the narratives in which the description of social relations plays so prominent a part. In this combination of social myths with those accounting for the creation of man himself I see only another indication of the complexity of Australian culture.

So far I have assumed without question that the narratives of the Arunta and other tribes of central Australia are myths, the pure product of the human imagination, serving to account for certain of their social institutions and customs. From a study of myths having natural phenomena as their subject I was led to formulate the principle that man does not make myths about the familiar and the uniform, but rather about that which is exceptional and inconstant. Then, applying this principle to myths having social conditions as their subject, I have tried to show that, in so far as such social conditions are the subject of myth in Australia, they can only be fully explained on the assumption that Australian society is complex and has arisen through the mixtures of peoples possessing different forms of social organisation. I suppose it to have been the sense of mystery aroused in one people by the social practices of another which acted as the seed and fertiliser of the mythic fancy.

It will follow that, if the Australian narratives are myths, they are not empty and meaningless fancies, but have a very definite sociological significance. If the principle which I have formulated is correct, Australian mythology 
provides clear evidence of a social condition of fundamental importance, the complex nature of Australian culture.

If, then, the Australian narratives are myths, they possess definite sociological significance. There remains to be considered the possibility that they are not myths. In an early part of this paper I pointed out an important feature which differentiates myths dealing with social conditions from those which have natural phenomena as their subject. In the case of narratives which give an account of social conditions, it is always possible that we have to deal, not with myths, but with historical traditions. I have now to consider this possibility.

All the narratives of central Australia with which I have been dealing have a remarkable similarity of content.' All of them give an account of beings, coming from the north, who introduced certain elements of the material and magicoreligious culture and modified the social institutions. It is a remarkable fact that the content of the narratives should thus point unmistakably to just such a mixture of cultures as I have been led to postulate on the assumption that the narratives are myths. I do not now propose to discuss how far the Australian narratives are historical or mythical, or to what extent they are compounded of both elements. I content myself with pointing out that, whether these narratives be historical traditions or myths, they lead to the same conclusion, the complexity of Australian culture. If the opponents of such complexity reject the view that these narratives are historical traditions, they still have to face the position it has been my purpose to establish this evening. These narratives are either historical or mythical, and, whichever alternative be chosen, we are led to the complexity of Australian culture. The opponents of this complexity can only escape from the dilemma by denying one or both of the two main principles on which my argument is based, viz. the fundamental character of social 


\section{The Sociological Significance of Myth.}

structure, and the failure of the familiar to arouse the mythic fancy.

There may be some who will accept this complexity and yet hold that it may have arisen through conditions present within Australia itself. It is possible that widely different forms of social organisation may have evolved in different parts of Australia, and that, when one of these was carried from one part of the continent to another by a movement of people, it seemed sufficiently strange to strike the imagination and become the subject of myth. It would be beyond the scope of this paper to consider this possibility, nor can I now attempt to develop the lessons to be learnt from the Australian narratives if their sociological signifcance be accepted. The object of this paper has been to formulate a principle to guide us in the study of social myth in general, and I have only chosen the Australians as my example because social myth seemed to be so well developed among them. I must leave for another occasion the inquiry into the exact nature of the social complexity which is indicated by the Australian narratives.

I cannot refrain, however, from concluding my paper with a suggestion that the main conclusion $I$ have reached may furnish the solution of a problem which I used to introduce my subject. One of the grounds on which Mr. Lang rejects the historicity of Arunta myth ${ }^{28}$ is that, as soon as the Inapertwa, or "undifferentiated animated bulks," became fully formed human beings with totems, they found themselves in possession of the distinction between elder and younger brother. The story runs that a number of newly made men and women were killed and eaten by certain evil beings called Oruncha. One man who had escaped the slaughter proceeded to search for his okilia or elder brother, and, when he had found his head, was able to bring him back to life. "How can we take as historical evidence," says Mr. Lang, "fables which transplant, into the first dawn

$$
{ }^{83} \text { Loc. cit., p. } 119 .
$$


The Sociological Significance of Myth. 331

of humanity, the terminology of the present classificatory system?" So long as we regard the narrative as an indigenous account of the origin or creation of mankind, so long will it be contradictory and not to be explained save as the uncontrolled and meaningless product of the rude imagination. If, on the other hand, the narrative records, though in mythical form, the settlement of one people among another who, though far inferior to the strangers in material culture and intelligence, yet possessed the classificatory system of relationship, it is no longer obscure or contradictory, but one which will, I hope, fit in with and confirm other results of the ethnological analysis of Australian culture.

W. H. R. RIVERS. 